\title{
Endocytosis of the Glutamate Receptor Subunit GluK3 Controls Polarized Trafficking
}

\author{
Deborah Huyghe, ${ }^{1,2}$ Julien Veran, ${ }^{1,2}$ Virginie F. Labrousse, ${ }^{1,2}$ David Perrais, ${ }^{1,2}$ Christophe Mulle, ${ }^{1,2}$ \\ and Françoise Coussen ${ }^{1,2}$ \\ ${ }^{1}$ University of Bordeaux, Interdisciplinary Institute for Neuroscience, and ${ }^{2}$ CNRS UMR 5297, F-33000 Bordeaux, France
}

\begin{abstract}
Kainate receptors (KARs) are widely expressed in the brain and are present at both presynaptic and postsynaptic sites. GluK3-containing KARs are thought to compose presynaptic autoreceptors that facilitate hippocampal mossy fiber synaptic transmission. Here we identify molecular mechanisms that underlie the polarized trafficking of KARs composed of the GluK3b splice variant. Endocytosis followed by degradation is driven by a dileucine motif on the cytoplasmic C-terminal domain of GluK3b in heterologous cells, in cultured hippocam$\mathrm{pal}$ neurons, and in dentate granule cells from organotypic slice cultures. The internalization of GluK3b is clathrin and dynamin2 dependent. GluK3b is differentially endocytosed in dendrites as compared to the axons. These data suggest that the polarized trafficking of KARs in neurons could be controlled by the regulation of receptor endocytosis.
\end{abstract}

\section{Introduction}

The primary function of ionotropic receptors (iGluRs) is to conduct fast excitatory synaptic transmission in the CNS, hence their specific localization in the postsynaptic density. Some iGluRs are also present at presynaptic terminals, where they regulate neurotransmitter release (Pinheiro and Mulle, 2008). Kainate receptors (KARs), composed of various combinations of the five subunits GluK1-5 (formerly referred as GluR5-7, KA1, and KA2), display a variety of functions that concur with the regulation of the activity of synaptic networks by actions at presynaptic and postsynaptic sites (Contractor et al., 2011). The electrophysiological analysis of KAR-subunit deficient mice has indicated that GluK2 and GluK3 are essential components of presynaptic autoreceptors (Contractor et al., 2001; Pinheiro et al., 2007). The rapid mode of action of presynaptic KARs to facilitate glutamate release (Schmitz et al., 2001; Pinheiro et al., 2007) and the biophysical properties of recombinant GluK2/GluK3 receptors (Schiffer et al., 1997; Perrais et al., 2009) have led to the hypothesis that GluK3-containing KARs are localized close to glutamate release sites in the presynaptic active zone, although this has not yet received direct confirmation.

GluK1, GluK2, and GluK3 exist as multiple isoforms derived from alternative splicing of their C-terminal domain containing

Received May 3, 2011; revised June 16, 2011; accepted June 16, 2011.

Author contributions:V.F.L. and F.C. designed research;D.H., J.V., and V.F.L. performed research;D.H., D.P., C.M., and F.C. analyzed data; C.M. and F.C. wrote the paper.

This study was supported by grants from the French Ministry of Higher Education (D.H.), the Centre National de la Recherche Scientifique, the Conseil Régional d'Aquitaine, the European Commission (EUSynapse Project, contract no. LSHM-CT-2005-019055, to C.M.), and the Agence Nationale de la Recherche (ANR PreSynGlu to C.M.). We thank Noelle Grosjean for RT-PCR experiments together with Marlene Maitre, who performed laser microdissection experiments at the Neurocentre Magendie (INSERM U862), Elisabeth Normand for taking care of the mice and neuronal cultures, Mario Carta for technical help, Mark McNiven for the gift of Dyn2 plasmids, and Alexandre Benmerah and Alice Dautry-Varsat for Eps15 CDNA. Microscopy was performed at the Bordeaux Imaging Center with the help of Philippe Legros, Christel Poujol, Laure Malicieux, Sébastien Marais, and Florian Levet.

Correspondence should be addressed to either Françoise Coussen or Christophe Mulle at the above addresses, E-mail: fcoussen@u-bordeaux2.fr or mulle@u-bordeaux2.fr.

DOI:10.1523/JNEUROSCI.2206-11.2011

Copyright $\odot 2011$ the authors $\quad 0270-6474 / 11 / 3111645-10 \$ 15.00 / 0$ critical determinants for receptor trafficking (Coussen, 2009). An RXR motif in GluK1c and GluK5 acts as an ER retention signal, preventing surface expression of these subunits (Hayes et al., 2003; Ren et al., 2003b; Jaskolski et al., 2004). In contrast, GluK2a is highly expressed at the cell surface and, when coassembled with other KAR subunits, promotes membrane delivery of KAR splice variants normally retained in the ER (Ren et al., 2003a; Jaskolski et al., 2004; Yan et al., 2004; Nasu-Nishimura et al., 2006). Trafficking of KARs depends on their specific interaction between their C-terminal domain and the intracellular machinery that controls plasma membrane localization. Moreover, GluK2containing KARs are subject to activity-dependent endocytic sorting, followed either by recycling or by degradation, thus providing a mechanism for both rapid and chronic changes in the number of functional receptors at the plasma membrane (Martin and Henley, 2004; Martin et al., 2008).

Molecular mechanisms that govern targeting of iGluRs to postsynaptic sites are well documented. In contrast, little is known on how glutamate receptors are targeted to presynaptic compartments. There are some indications for the polarized trafficking of the metabotropic glutamate receptor mGluR7, which localizes presynaptically in vivo to regulate neurotransmitter release (Sansig et al., 2001). Its dynamic regulation at the neuronal membrane appears to control bidirectional plasticity at hippocampal synapses (Pelkey et al., 2005). The presynaptic clustering of mGluR7 requires an interaction of a PDZ domain with PICK1 (Boudin et al., 2000), which is dependent on phosphorylation by PKC (Bertaso et al., 2008; Suh et al., 2008).

There are two splice variants of GluK3, named GluK3a and GluK3b (Schiffer et al., 1997). GluK3a shares the same C-terminal export motif as GluK2a, which allows high expression at the plasma membrane. In contrast, GluK3b seems to be retained in the ER and is only detected at the plasma membrane when coexpressed with GluK3a (Jaskolski et al., 2005c). Here we have studied the mechanisms of polarized trafficking of GluK3 with a main focus on GluK3b. We show that the subcellular lo- 
calization of GluK3b depends on an endocytic process that controls the polarized trafficking of KARs in neurons.

\section{Materials and Methods}

Antibodies and reagents. Primary antibodies were as follows: monoclonal anti-myc (9E10) (Roche); monoclonal anti-AnkyrinG (Neuromab); polyclonal anti-myc and anti-R6R7NL9 (Millipore Biotechnology); and polyclonal anti-GFP (Invitrogen). Secondary antibodies were as follows: Alexa Fluor-568 goat antirabbit, Alexa Fluor-568 goat anti-mouse, Alexa Fluor-488 anti-mouse, and Alexa Fluor-647 goat anti-mouse (Invitrogen). For Western blots, secondary peroxidase-labeled antibodies were obtained from P.A.R.I.S Biotechnology.

DNA constructs. Myc-GluK3a and mycGluK3b are described by Jaskolski et al. (2005c). For production of GFP-GluK3, DNA corresponding to GFP was amplified from pEGFP vector using primers containing corresponding restriction sites to replace the 6-myc epitope by GFP by subcloning. Mutation of the two leucines (\#882 and \#881 of wild-type GluK3b) to alanines in the C-terminal domain of GluK3b was performed by directed mutagenesis using QuikChange XL kit (Stratagene). Clones were sequenced before use.

Cells and transfection. COS-7 cells were maintained and transfected using FUGENE 6

(Roche Molecular Biochemicals) as by Jaskolski et al. (2004). Primary cultures of hippocampal neurons were obtained from 1-d-old pups of GluK3 $^{-1-}$ mutant mice (Jaskolski et al., 2004) and were transfected using LIPOFECTAMINE 2000 (Invitrogen) according to the manufacturer's indications.

$R T-P C R$. The dentate gyrus was selectively captured on two different Laser Capture Microdissection (LCM) caps. Total RNA was isolated using the RNeasy Plus micro kit (Qiagen) as described by the manufacturer. RNA quality was assessed by capillary electrophoresis (Agilent RNA Bioanalyseur). Total RNA was reverse transcribed using random primers (100 pmol) and RevertAid (200 U) with RevertAid kit as described by the manufacturer (Fermentas). After reverse transcription reaction, cDNAs were stored at $-20^{\circ} \mathrm{C}$. CDNAs coding for GluK3a and GluK3b were amplified with a first PCR between oligonucleotides \#1 (5'-CGGCTCTGAGGTGGTGGAGAATAAC-3') and \#5 (5'-GCTGGCTATGGAGATGGTCGGTG-3') for 30 cycles. To detect GluK3a, a second round of PCR was performed with oligonucleotides \#1 and \#4 (5' GCTGTGGCTTGTGCTTGAGACGC3'). The corresponding product was restriction digested with EcoN1 to cut DNA corresponding to GluK3b as shown in Figure 1 for the GluK3a and GluK3b plasmids. To detect GluK3b, two rounds of PCR were necessary with oligonucleotides \#2 (5'-GGCCCTGGAGGAGGCTGCG-3') and \#4 followed by \#3 (5'AGGCTGCGTTGGACAGGG-3') and \#4.

Labeling of extracellular and intracellular receptors by immunocytochemistry. For COS-7 cells, $24 \mathrm{~h}$ after transfection with GFP-tagged receptors, anti-GFP polyclonal antibodies $(1: 400)$ were incubated in culture medium at $4^{\circ} \mathrm{C}$ for $1 \mathrm{~h}$. Cells were then fixed. Cells were incubated with an Alexa Fluor-568 (red) anti-rabbit antibody (1:1000) for $30 \mathrm{~min}$ at room temperature and mounted with Vectashield media. For hippocampal neurons, $24 \mathrm{~h}$ after transfection with the different myc-tagged receptors, labeling of extracellular and intracellular receptors was performed as by Jaskolski et al. (2004). Colocalization of receptors with GFP-Rab7 was performed after different times of endocytosis as indicated in Figure 4. Percentage of receptors colocalized with GFP was calculated as by Jaskolski et al. (2005c). Immunofluorescence was visualized with an upright epifluorescence microscope (Leica Microsystems). Image acquisition was performed with a LEICA camera and the MetaMorph analysis

B

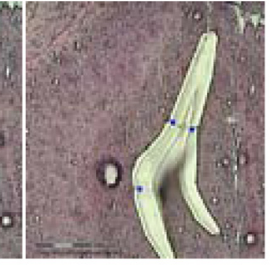

GluK3a

3b c1 C2

D

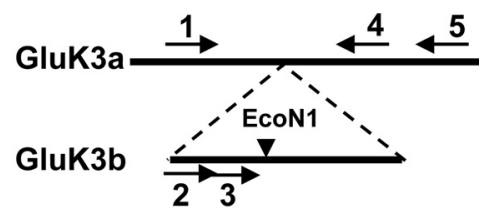

GluK3b
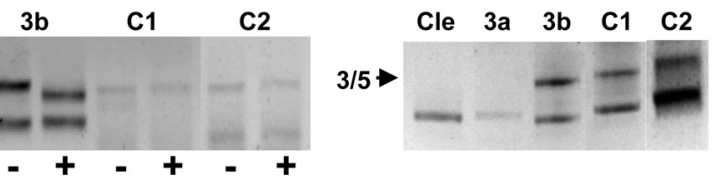

.

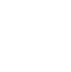

\section{PQAPVIVKTE888}

\section{RSFCSAMVEELRMSLKCQRRLKHKPQAPVIVKTE ${ }^{88}$}

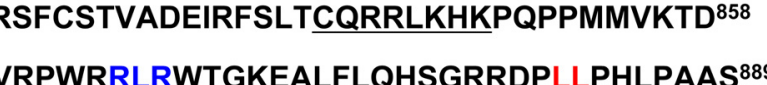

Figure 1. GluK3a and GluK3b RNA are present in the dentate gyrus. $A$, Pictures of the dentate gyrus before and after recurring of the region. $\boldsymbol{B}$, Schematic picture of RNA coding for GluK3a and GluK3b and corresponding oligonucleotides used for the PCRs. $\boldsymbol{C}$ ,PCR products from control (without DNA), plasmids coding for GluK3 subunits ( $3 \mathrm{a}, 3 \mathrm{~b}$ ), and two samples from dentate gyrus ( $\mathrm{C}$ oligonus GluK2a and GluK3a are underlined, and RXR and LL motifs of GluK3b are labeled in blue and red, respectively.

software. Images were mounted with ImageJ. Images were analyzed with the MATLAB software. Statistical analyses were made with PRISM.

Colocalization assay with Rab5a. A series of images with an interval of $0.2 \mu \mathrm{m}$ in the $z$-axis was captured with a spinning disk microscope (Leica DMI6000, Leica Microsystems). Camera aperture, magnification, light power, and exposure time were fixed for all images. Images were processed with MetaMorph software (Molecular Devices). A minimum of 15 COS-7 cells from each repeated experiments $(n=3)$ were acquired randomly. The analysis of colocalization of GluK3 and Rab5 was performed using the "Colocalization" module of the image calculator process of ImageJ version 1.43 (Scion Image). A homemade macro was used to analyze the entire confocal stack by measuring the intensity of fluorescence in each confocal plane using fixed threshold intensities.

Endocytosis assay. To follow endocytosis of tagged receptors, anti-myc monoclonal antibody diluted (1:500) in conditioned culture medium was incubated on live cells for $30 \mathrm{~min}$ at $37^{\circ} \mathrm{C}$. Cells were washed twice in PBS $1 \times$ at $4^{\circ} \mathrm{C}$ and then incubated with Alexa Fluor-568 (red) antimouse antibody $(1: 500)$ for $30 \mathrm{~min}$ at $4^{\circ} \mathrm{C}$ for COS-7 cells and at $16^{\circ} \mathrm{C}$ for neurons to label surface receptors. Cells were washed twice with PBS $1 \times$ and fixed for $15 \mathrm{~min}$ in $4 \%$ paraformaldehyde, $4 \%$ sucrose in PBS. After three washes in PBS, cells were incubated for $10 \mathrm{~min}$ at room temperature with $50 \mathrm{~mm} \mathrm{NH}_{4} \mathrm{Cl}$ in PBS- $0.3 \%$ BSA to quench aldehyde groups and then permeabilized in PBS- $0.3 \%$ BSA- $0.3 \%$ Triton X-100 for 2 min for COS-7 cells and in PBS- $0.3 \%$ BSA-0.05\% saponin for 15 min for neurons. Cells were then incubated for $30 \mathrm{~min}$ at room temperature with Alexa Fluor-488 (green) anti-mouse secondary antibody (1:1000) to label endocytosed receptors. Cells were washed several times in PBS- $0.3 \%$ BSA and mounted in Vectashield. Immunofluorescence was quantified with the MATLAB program. The amount of endocytosed receptors corresponds to the ratio between green pixels only on green plus red pixels.

Biotinylation assay. COS-7 cells were transfected in six-well plates (two wells per condition) with an expression vector encoding myc-tagged GluK3. Biotinylation assay was performed as by Jaskolski et al. (2004). The beads were diluted in $80 \mu \mathrm{l}$ of gel loading buffer. The lysates and the extracted beads were analyzed by Western blotting using the appropriate antibody. Images were acquired by Syngene, and quantification was performed by GeneTools software. The percentage of extracellular receptors 

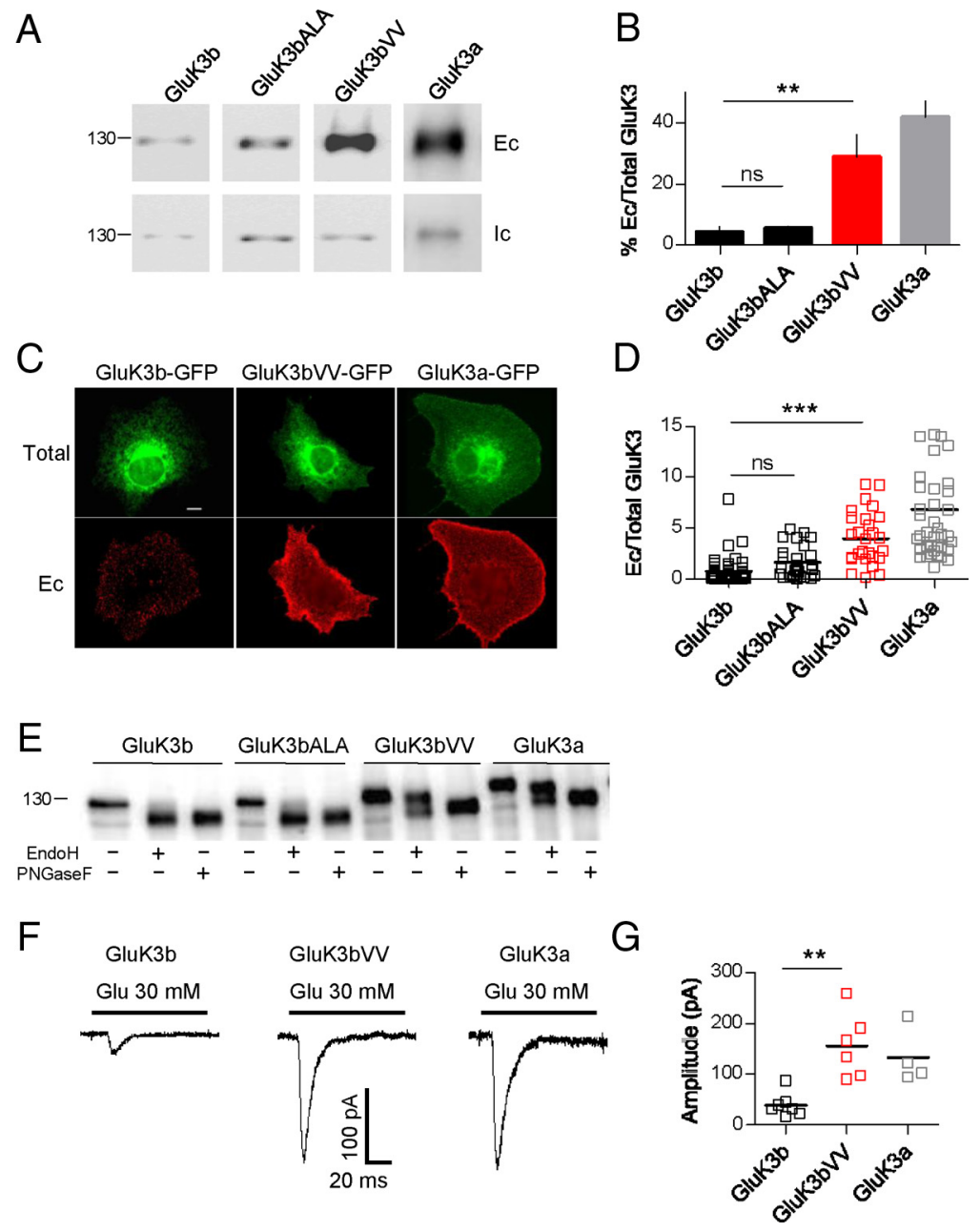

Figure2. Mutation of GluK3b dileucinemotifincreases its plasma membrane localization in COS-7 cells. $A$, Representative Western blot of extracellular (Ec) and intracellular (Ic) myc-GluK3a and myc-GluK3b (WT and mutants) expression in transfected COS-7 cells. B, Quantification of extracellular GluK3a or GluK3b (WT and mutants) amount divided by total amount of receptors (Ic $+\mathrm{Ec}$ ). Histograms show the means \pm SEM ( $n=5$ experiments). C, Representative image of COS-7 cells transfected by GluK3a or GluK3b-GFP (WT and mutants). The first row shows total expression of GluK3-GFP. The second row shows extracellular receptors labeled in red (anti-GFP). Scale bar, $10 \mu \mathrm{m}$. D, Quantification of the amount of Ec GluK3 (number of red pixels) divided by the amount of total receptors (number of green pixels, $n>30$ ) ( $n=4$ experiments). $\boldsymbol{E}$, Enzymatic digestion of GluK3a and GluK3b (WT and mutants) by EndoH and PNGaseF as labeled. $\boldsymbol{F}$, Representative traces of whole-cell currents in HEK-293 cells transfected with GluK3a, GluK3b, and GluK3bVV after application of 30 mm glutamate for 100 ms. G, Quantification of currents for each proteins.

was given as follows: $\mathrm{EC} /(\mathrm{EC}+\mathrm{IC}) \times 100$, where $\mathrm{EC}$ is the number of extracellular receptors and IC is the number of intracellular receptors.

Degradation assay. The day before the experiment, COS-7 cells transfected with myc-tagged GluK3 were pooled and plated in six-well plates to avoid variability in transfection efficiency between wells. Cells were washed twice in ice-cold PBS, $\mathrm{pH} 8$, and incubated with $1 \mathrm{ml}$ of sulfo-NHS-SS-Biotin (Pierce) diluted in $\mathrm{PBS}, \mathrm{pH} 8$, for $30 \mathrm{~min}$ at $4^{\circ} \mathrm{C}$. Cells were washed twice in PBS, pH 8, and then incubated in glycine (100 mM) diluted in PBS, $\mathrm{pH} 8$, for $30 \mathrm{~min}$ at $4^{\circ} \mathrm{C}$. After two washes in PBS, two wells were kept at $4^{\circ} \mathrm{C}(T=0)$ in ice-cold PBS and the others were incubated for different times at $37^{\circ} \mathrm{C}$ in prewarmed PBS. Cells were lysed by scraping in $500 \mu \mathrm{l}$ of lysis buffer [150 mM NaCl, 1\% Triton X-100 (Sigma-Aldrich), 25 mм HEPES (Invitrogen), and protease inhibitors] and lysed on a row for $1 \mathrm{~h}$ at $4^{\circ} \mathrm{C}$. After spun at 8000 rpm for $15 \mathrm{~min}, 25 \mu \mathrm{l}$ of each clarified lysate was kept for total protein quantification (BCA dosage, Pierce). The rest of the lysate was incubated overnight at $4^{\circ} \mathrm{C}$ with $30 \mu \mathrm{l}$ of streptavidin-agarose beads. Beads were washed three times at $4^{\circ} \mathrm{C}$ in lysis buffer and once in Tris- $\mathrm{HCl}, \mathrm{pH}$ 7.4, and then incubated in $80 \mu \mathrm{l}$ of gel loading buffer. The lysates and the extracted beads were analyzed by Western blotting using the appropriate antibody. Images were acquired and analyzed as described. Degradation of biotinylated receptors over time was calculated as the percentage of biotinylated receptors at time $T /$ percentage of biotinylated receptors at time $T_{0}$ adjusted at the same protein concentration.

Electrophysiology. Cells were transfected using FUGENE 6 with GFP and GluK3a, GluK3b, or the GluK3b mutant (GluK3b VV) at a cDNA ratio of 1:3. To study whether Eps15 is involved in the GluK3b endocytosis process, these two cDNAs were cotransfected with GFP at a ratio of 1:1.5:1.5. One day after transfection, cells were bathed in HEPES-buffered solution (HBS) containing the following (in $\mathrm{mm}$ ): 145 $\mathrm{NaCl}, 2 \mathrm{KCl}, 2 \mathrm{MgCl}_{2}, 2 \mathrm{CaCl}_{2}, 10$ glucose, and 10 HEPES, adjusted to $320 \mathrm{mOsm}$ per liter and pH 7.4 with $\mathrm{NaOH}$, at room temperature. Whole-cell recordings were performed on green fluorescent cells lifted off the coverslip, placed under the flow of a theta tube, and held at -80 to $-40 \mathrm{mV}$. Recording pipettes (resistance 4-6 M $\Omega$ ) were filled with a solution containing the following (in mM): $130 \mathrm{CsCH}_{3} \mathrm{SO}_{3}$, $2 \mathrm{NaCl}, 2 \mathrm{MgCl}_{2}, 10$ EGTA, 10 HEPES, 4 $\mathrm{Na}_{2} \mathrm{ATP}$, and 0.1 spermine, adjusted to 310 mOsm per liter, and $\mathrm{pH} 7.2$ with $\mathrm{CsOH}$. Currents were evoked by long application of $30 \mathrm{~mm}$ glutamate for $100 \mathrm{~ms}$ every $20 \mathrm{~s}$ by moving the theta tube laterally with a piezoelectric device, under computer control.

Polarization assay. Dissociated cultured neurons were cotransfected at DIV10 with cDNAs encoding pDsred and myc-GluK3b or mycGluK3bVV. At DIV 12, membrane receptors were labeled with an anti-myc (rabbit) antibody in PBS-BSA $0.3 \%$. Cells were fixed (4\% PFA) and permeabilized in PBS-BSA-saponin $0.05 \%$ for $30 \mathrm{~min}$. The AIS (axon initial segment) was labeled with anti-Ankyrin-G (mouse). We then applied secondary antibodies in PBSBSA-saponin (Alexa Fluor rabbit 488 and Alexa Fluor mouse 567). Cells were washed several times in PBS-BSA $0.3 \%$ and mounted in Vectashield. Immunofluorescence was quantified with the MATLAB program. To quantify the surface of axons and dendrites, we cotransfected each receptor cDNAs with a vector coding for the fluorescent protein pDsRed. Axons were identified using ankyrin-G labeling. For each compartment, the density of receptors was calculated by dividing the average intensity of green fluorescence (extracellular receptors) by the number of red pixels (corresponding to the surface). The same experiments were performed with a dominant-negative of Eps15.

Organotypic slice assay. Experiments were conducted by using a biolistic gene gun system to propel pDsRed and GFP-GluK3b or GFPGluK3bVV cDNA-coated particles into hippocampal organotypic slices as described by Desimoni et al. (2006). Slices were fixed $4 \mathrm{~d}$ after transfection for $4 \mathrm{~h}$ in $4 \%$ paraformaldehyde at $4^{\circ} \mathrm{C}$ and immunostained for GFP (rabbit) and ankyrin G (mouse). Primary $\left(1: 500 ; 24 \mathrm{~h}\right.$ at $\left.4^{\circ} \mathrm{C}\right)$ and secondary antibodies (Alexa Fluor rabbit 488 and Alexa Fluor mouse $647,1 / 1000 ; 4 \mathrm{~h}$ at room temperature) were applied in PBS/NGS buffer [0.1 M phosphate buffer, $\mathrm{pH} 7.4$, containing $0.3 \%$ normal goat serum (NGS) and $0.3 \%$ Triton X-100]. Transfected neurons (6 GluK3b and 10 GluK3bVV) were chosen randomly for qualitative analysis from four different organotypic cultures (two independent experiments). Images of GFP/pDsRed-labeled neurons in the dentate gyrus were acquired by using the spinning disk microscope DMI6000 (Leica) with a $40 \times$ objective. For each image, a series of pictures with an interval of $0.2 \mu \mathrm{m}$ in the $z$-axis were acquired. Camera aperture, magnification, light power, and exposure time were fixed for all images. The maximal $z$-projection was 
used for the colocalization analysis of GluK3, pDsRed, and ankyrinG using MetaMorph software (Molecular Devices).

\section{Results}

GluK3a and GluK3b transcripts are present in dentate granule cells

There is strong indication that presynaptic GluK3-containing KARs are present at hippocampal mossy fiber synapses originating from dentate granule cells (Pinheiro et al., 2007). We first checked whether dentate granule cells express mRNAs for both GluK3a and GluK3b (Fig. 1). We specifically laser captured the dentate gyrus (Fig. 1A) and performed RT-PCR with oligonucleotides as indicated in Figure $1 \mathrm{~B}$. Both GluK3a and GluK3b mRNAs were detected in samples of the dentate gyrus (Fig. 1C,D). Both isoforms, either alone or in combination, potentially compose presynaptic KARs. GluK3a and GluK3b share the same amino acid sequence in their $\mathrm{N}$-terminal and transmembrane domains but contain distinct cytoplasmic C-terminal sequences of 80 and 71 aa, respectively. GluK3a possesses an export motif (CQRRLKHK) similar to GluK2a that ensures efficient targeting to plasma membrane, whereas GluK3b displays a RXR motif followed by a dileucine motif (Fig. 1E) (Jaskolski et al., 2004). In contrast with GluK1c, GluK5, and other ion channels, the RXR motif of GluK3b does not act as an ER retention motif, but might be involved during the assembly process (Jaskolski et al., 2005c). A dileucine motif has been shown to be important for the trafficking of GluK5 (Ren et al., 2003b). More generally, dileucine motifs are thought to be involved in endocytosis (Barbosa et al., 2002; Garrido et al., 2003; Zhao et al., 2008). Whether the dileucine motif is important for the trafficking of GluK3b is not yet known.

\section{Mutation of a dileucine motif in} GluK3b increases plasma membrane expression in COS-7 cells

To clarify the rules of GluK3b trafficking and its polarized expression in neurons, we first studied the role of the dileucine motif (L881L882) for the plasma membrane localization of homomeric GluK3b expressed in COS-7 cells. We analyzed the consequences of the mutation of the two leucines into two valines (GluK3bVV). We first quantified the relative level of expression of extracellular GluK3a, GluK3b, GluK3bVV, and GluK3b-ALA (a mutant in which the arginine of the RXR motif were replaced by alanine), in biotinylation assays (Fig. 2A). As shown previously, GluK3a is highly expressed at the plasma membrane and the level of expression of GluK3b-ALA does not significantly differ from GluK3b (Jaskolski et al., 2005c). In contrast, mutation of the dileucine motif led to a 6.6-fold

A

E
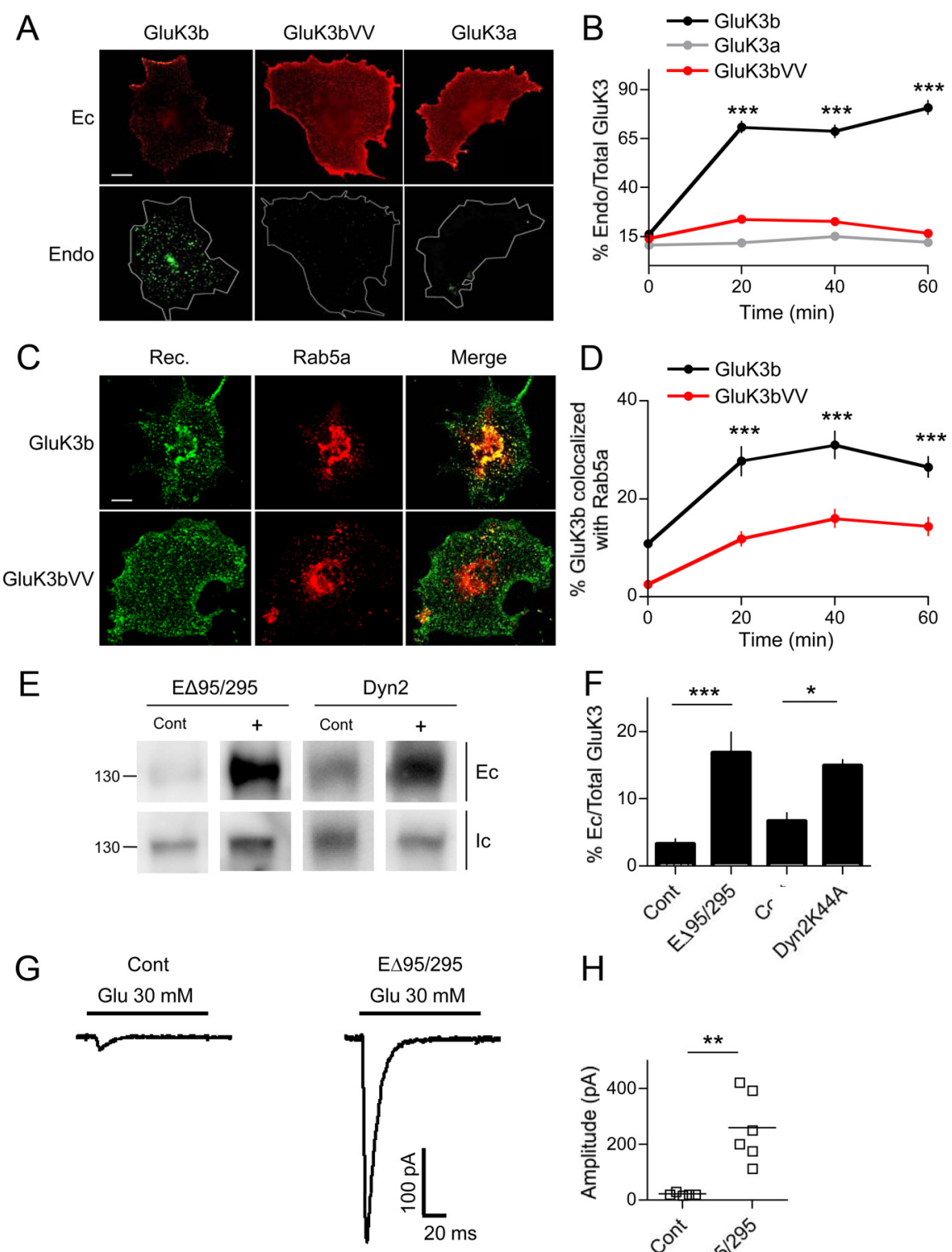

$\mathrm{H}$

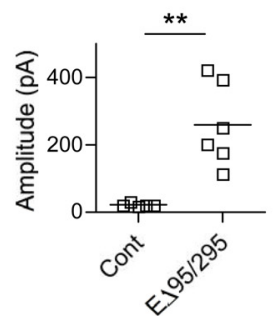

Figure 3. GluK3b is exported to the plasma membrane and internalized through clathrin-dependent endocytosis. $A$, Representative images of extracellular and endocytosed localization of myc-GluK3a, myc-GluK3b, and myc-GluK3bVV transfected in COS-7 cells. The first row represents extracellular receptors in red (Ec). The second row shows endocytosed receptors in green (Endo). Scale bars represent $10 \mu \mathrm{m}$. The shape of the cells has been drawn by hand. $B$, Quantification of the ratio between endocytosed and total receptors over time ( $n>30$ for each construct, $n=3$ experiments). $C$, Representative images of extracellular and endocytosed myc-GluK3b colocalized with Rab5a over time. The first column shows GluK3b labeled in green (WT and mutant), and the second column shows Rab5a labeled in red. The third column shows the merge. D, Quantification of colocalization between GluK3b (green pixels) and Rab5a (red pixels). $\boldsymbol{E}$, Representative Western blot of extracellular (EC) and intracellular (Ic) expression myc-GluK3b constructs expressed with Eps 15 or Dyn2 mutants in transfected COS-7 cells. The molecular weight is in kilodaltons. $F$, Quantification of Ec receptors divided by total receptors (IC $+\mathrm{Ec})(n=3$ experiments). $\mathbf{G}$, Representative traces of currents activated by glutamate (10 mm) in HEK-293 cells with cotransfected GluK3b and Eps 15 mutants. $\boldsymbol{H}$, Quantification of the amplitude of currents in each condition ( $n>5$ for each condition).

increase in the plasma membrane expression of GluK3b (percentage of EC/total receptors, GluK3b: $4 \pm 2 \%$, GluK3bVV: $29 \pm 7 \%, n=5, p<0.01$, one-way ANOVA Bonferroni's multiple-comparison test) (Fig. $2 B$ ). We confirmed these results using immunocytochemistry in COS-7 cells expressing GFPGluK3a/b or mutants tagged in their $\mathrm{N}$ terminus with GFP. We labeled receptors expressed in the plasma membrane with an antibody against GFP (revealed in red) in nonpermeabilized cells, and we normalized the fluorescence to the amount of total GFP 
fluorescence (in green) (Fig. 2C). This ratio (EC/total) was significantly higher for GluK3bVV than for GluK3b (percentage of EC/total receptors, GluK3b: $0.7 \pm 0.2 \%$, GluK3bVV: $3.9 \pm 0.5 \%$, arbitrary units, $n=3, p<0.001$ one-way ANOVA Bonferroni's multiple-comparison test) (Fig. 2D). In addition, GluK3b and GluK3b-ALA were sensitive to EndoH in contrast to GluK3bVV, which appeared resistant to this enzyme, like GluK3a (Fig. 2E). This may suggest that GluK3b and GluK3b-ALA are retained in the ER and that mutation of the dileucine motif allows GluK3b to exit the ER and to be exported at the plasma membrane. Parallel electrophysiological experiments, using whole-cell recordings on transfected HEK-293 cells, showed an increase in the peak amplitude of currents evoked by fast application of glutamate for GluK3bVV as compared to GluK3b, to levels similar to GluK3a (current amplitudes in pA, GluK3b: $39 \pm 9, n=7$, GluK3bVV: $156 \pm 26, n=6$, GluK3a: $133 \pm 28, n=4, p<0.01$ one-way ANOVA Bonferroni's multiple-comparison test) (Fig. $2 F, G)$. All these results support the idea that GluK3b is retained in the ER. However, due to the reported role of the dileucine motif in endocytosis, another possibility could be that GluK3b is exported to the plasma membrane and then rapidly endocytosed, explaining the low amount of GluK3b localized at the plasma membrane.

\section{GluK3b is exported to the plasma membrane then} internalized through a clathrin-dependent pathway

To test this hypothesis, we quantified endocytosis of GluK3a, GluK3b, and GluK3bVV in COS-7 cells using the following assay (Fig. $3 A, B$ ). After transfection with myc-tagged receptors, COS-7 cells were incubated with a primary anti-myc antibody for $30 \mathrm{~min}$ at $37^{\circ} \mathrm{C}$. Receptors expressed at the cell surface were labeled in red, whereas endocytosed receptors were labeled in green after fixation and permeabilization (see Materials and Methods). Images were analyzed with a MATLAB program that differentiates endocytosed receptors (green pixels only) and extracellular receptors (red pixels only) (Jaskolski et al., 2005b). The level of endocytosis was evaluated by measuring the ratio between the number of green pixels only (endocytosed) and total pixels (green only + red only). During the 30 min incubation period, $37 \pm 2 \%(n=32)$ of GluK3b is endocytosed as compared to $12 \pm$ $1 \%(n=34)$ for GluK3a. Mutation of the dileucine motif markedly decreased endocytosis of GluK3b to levels comparable to that of GluK3a $(14 \pm 1 \%, n=43, p<0.001$ one-way ANOVA Bonferroni's multiple-comparison test) (Fig. $3 B$ ). This result suggests that GluK3b is not retained in the ER, as initially proposed (Jaskolski et al., 2005c), but rather exported to the plasma membrane, and then rapidly endocytosed. The constant internalization likely explains the low amount of GluK3b localized at the plasma membrane in previous experiments. To confirm these results, we performed colocalization experiments between endocytosed GluK3b or GluK3bVV and Rab5a, a marker of early endosomes (Fig. 3C). We observed that the colocalization between GluK3b and Rab5a markedly increases over time $(9 \pm 2 \%$ at time $0 \mathrm{~min}, n=31 ; 31 \pm 3 \%$ at time $40 \mathrm{~min}, n=41, p<0.001$ one-way ANOVA Bonferroni's multiple-comparison test), whereas the rate of colocalization between GluK3bVV and Rab5a remains significantly lower $(2.5 \pm 0.5 \%$ at time 0 min, $n=45$; $16 \pm 2 \%$ at time $40 \mathrm{~min}, n=44$ ) (Fig. $3 D$ ). This result confirms that GluK3b is endocytosed and that endocytosis depends on the dileucine site.

To further characterize GluK3b internalization, we tested whether GluK3b was endocytosed by a clathrin-dependent pathway using dominant-negative forms of Eps15 (ED25/295), as compared to the control Eps15 form D3 2 (Benmerah et al.,

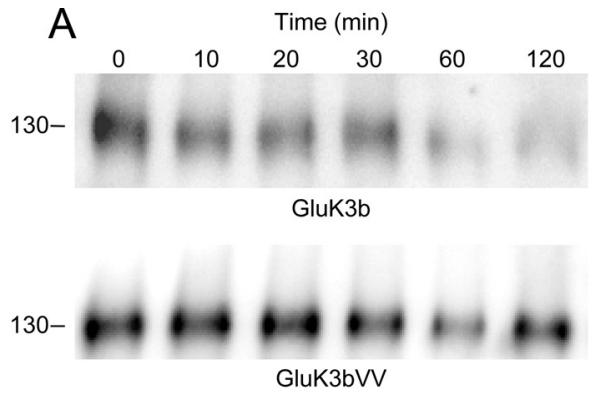

B
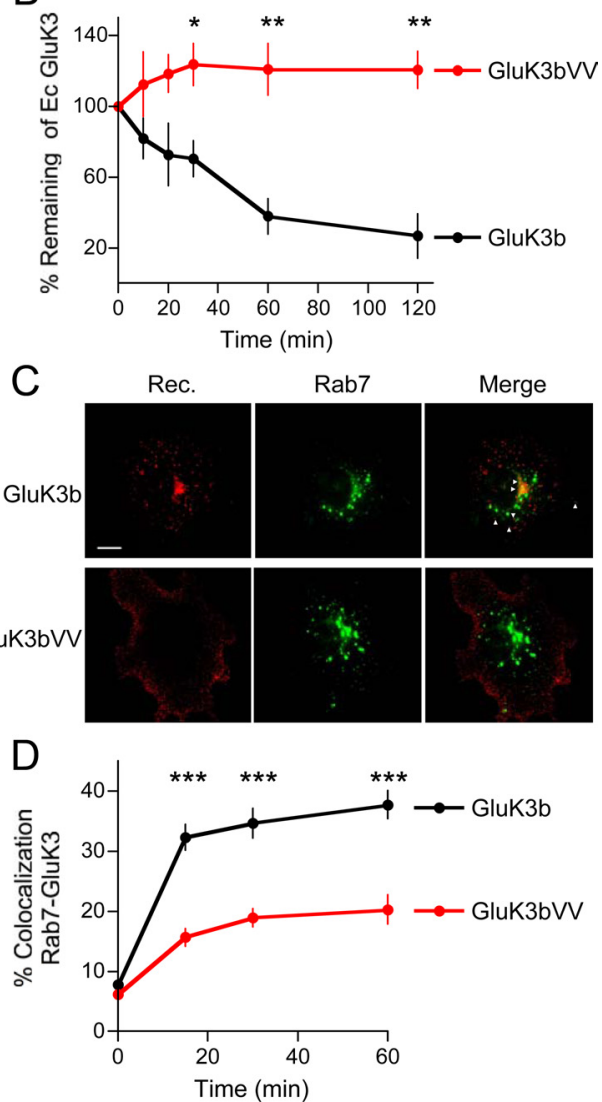

Figure 4. GluK3b internalization is followed by degradation. $A$, Representative Western blot biotinylated myc-GluK3b receptors indicating degradation over time in COS-7 cells. B, Quantification of myc-GluK3b degradation (WT and mutants). The amount of remaining biotinylated receptors is normalized to the total amount of proteins (BCA dosage). Plots show the mean \pm SEM ( $n=3$ independent experiments). C, Representative images of colocalization between GluK3b (WT and mutant) and Rab7-GFP at 60 min. The first column shows GluK3 labeled in red, and the second column shows Rab7 tagged in green. The third column shows the merge. $\boldsymbol{D}$, Quantification of the colocalization between Rab7-GFP (green pixels) and GluK3 (red pixels) over time. Plots show the mean \pm SEM (50 cells, $n=3$ experiments).

1998). We also tested whether GluK3b internalization was dependent on dynamin using Dynamin2 (Dyn2) and the dominantnegative mutant Dyn2K44A (Cao et al., 1998). Following coexpression of GluK3b with Eps 15 or Dyn 2 constructs in COS-7 cells, we evaluated the amount of extracellular GluK3b by a biotinylation assay (Fig. 3E). Coexpression of dominant-negative forms of Eps 15 and Dyn2 significantly increased the levels of extracellular GluK3b ( $p<0.01$, one-way ANOVA Bonferroni's multiple-comparison test) (Fig. $3 F$ ), indicating that GluK3b is internalized through clathrin- and Dyn2-dependent pathways ( $3 \pm 1 \%$ in control; $17 \pm 3 \%$ in $\mathrm{E} \Delta 25 / 295,7 \pm 1 \%$ in control, $15 \pm 1 \%$ in Dyn2K44A, $p<0.001 ; n=3$ experiments). Con- 
versely, the level of extracellular GluK3a and GluK3bVV was not altered by coexpression with dominant-negative forms of Eps15 and Dyn2 (GluK3a: $33 \pm 3 \%$ in control; $27 \pm 3 \%$ in $\mathrm{E} \Delta 25 / 295,37 \pm 2 \%$ in control, $33 \pm 3 \%$ in Dyn2K $44 \mathrm{~A} ; n=3$ experiments; GluK3bVV: $20 \pm 4 \%$ in control; $25 \pm 3 \%$ in $\mathrm{E} \Delta 25 / 295,24 \pm 4 \%$ in control, $23 \pm 4 \%$ in Dyn2K $44 \mathrm{~A}, n=3$ experiments) (not shown). We also measured the amplitude of GluK3b currents from HEK-293 cells cotransfected with GluK3b and the dominant-negative forms of Eps15 (Fig. 3G,H). In agreement with the biotinylation experiments, we found that blocking clathrin-mediated endocytosis led to increased amplitude of glutamateevoked currents, indicating an increased density of surface GluK3b receptors (current amplitudes, GluK3b with D3 $\Delta 2: 22 \pm 1$ $\mathrm{pA}, \quad n=5$, GluK3b with $\mathrm{E} \Delta 95 / 295$ : $259.43 \pm 3 \mathrm{pA}, n=6, p=0.002$, unpaired $t$ test), whereas the amplitude of GluK3a or GluK3bVV currents were not affected by coexpression of Eps15 and Dyn2 (not shown). Altogether, these results confirm that GluK3b is exported to the plasma membrane, where it is rapidly endocytosed through a clathrin- and Dyn2-dependent mechanism.

\section{GluK3b internalization is followed by degradation}

Since GluK3b is exported from the ER to the plasma membrane through the Golgi apparatus, we should have been able to detect EndoH-resistant GluK3b (Fig. 2F). The fact that our deglycosylation experiments only detected immature GluK3b can be explained if GluK3b is degraded constitutively just after its internalization. To test this hypothesis, we measured the degradation of GluK3b over time in COS-7 cells using biotinylation and immunocytochemistry experiments (Fig. 4). We performed a biotinylation assay on six different plates of COS-7 cells originating from the same transfected cultures with GluK3b or GluK3bVV. After biotinylation, plates were reincubated for different times at $37^{\circ} \mathrm{C}$. Cells were lysed and biotinylated proteins were purified on streptavidin beads. The remaining amount of biotinylated receptors at the right molecular weight was then revealed by Western blotting (Fig. 4A) (see Materials and Methods). Time 0 represents the plates that have been kept at $4^{\circ} \mathrm{C}$, a temperature at which trafficking of proteins is abrogated. The amount of extracellular GluK3b at time 0 is the reference value for the other plates incubated at $37^{\circ} \mathrm{C}$ (100\%) (Fig. $4 \mathrm{~B}$ ). These experiments demonstrate a progressive decline in the amount of biotinylated GluK3b (decrease by $60 \%$ after $1 \mathrm{~h}$ at $37^{\circ} \mathrm{C}$, by $80 \%$ after $2 \mathrm{~h}$ ) that is due to degradation of receptors labeled at $T_{0}$. In contrast, the amount of biotinylated GluK3bVV does not change over time, indicating that blocking GluK3b internalization also blocks its degradation (three experiments, $T_{20}$
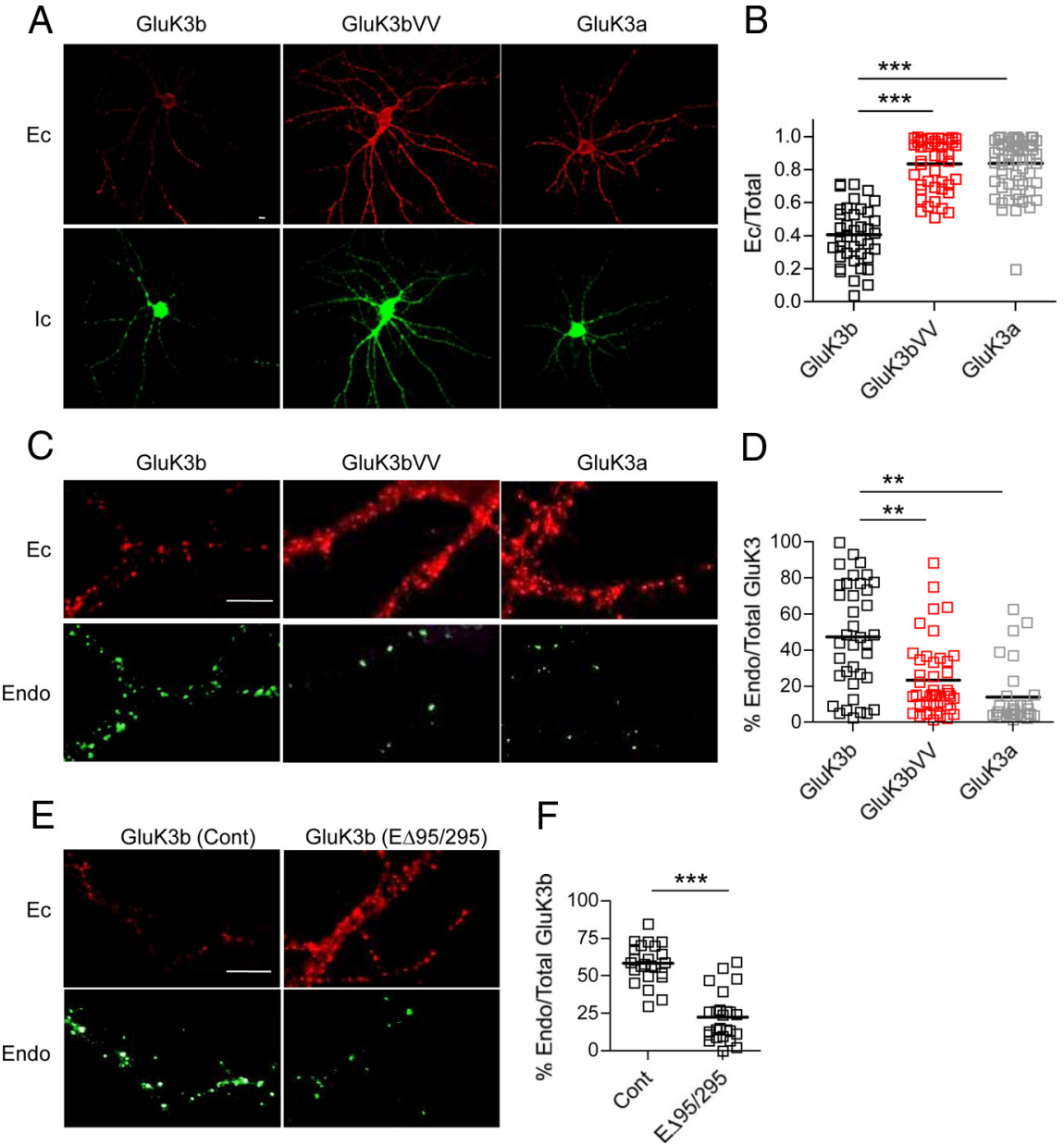

Figure 5. The dileucine is an endocytosis motif for GluK3b in hippocampal neurons. GluK3b are endocytosed through a clathrindependent pathway. $\boldsymbol{A}$, Representative images of extracellular (Ec) and intracellular (IC) GluK3 receptors labeling in neurons ( the total amount of receptors $(E C+I C)$. The line shows the mean ( $n>30$ in 3 experiments). $C$, Representative images par (EC) and endocytosed (Endo) Gluk3 receptors in neurons transfected with either GluK3a, Gluk3b or GluK3bV. The tosed receptors labeled in green in the same region. Scale bars represent $10 \mu \mathrm{m}$. D, Quantification of the amount of endocytosed (Endo) divided by the total amount of receptors (Ec + Endo). The quantification of endocytosed receptors have been made in the total cell. The line shows the mean ( $n>30$ in 3 experiments). $\boldsymbol{E}$, Representative images of extracellular (EC) and endocytosed (Endo) GluK3 receptors in neurons cotransfected with Eps15 (WT or mutant). The first panel shows the extracellular same region. Scale bars represent $10 \mu \mathrm{m}$. $\boldsymbol{F}$, Quantification of the amount of endocytosed receptors (Endo) divided by the tota amount of receptors $(E c+E n d o)$. The quantification of endocytosed receptors have been made in the total cell. The line shows the mean ( $n>30$ in 3 experiments).

$p=0.09, T_{30} p=0.03, T_{60} p=0.009, T_{120} p=0.005$, unpaired $t$ test) (Fig. $4 B$ ). We performed colocalization experiments between GluK3b (or GluK3bVV) and the lysosomal marker Rab7GFP over time (Fig. 4C). At time 0, no colocalization between Rab7 and GluK3b was observed, indicating that the labeling was specific. After $15 \mathrm{~min}$ at $37^{\circ} \mathrm{C}$, we observed $30 \pm 1 \%$ (yellow pixels in red pixels) colocalization between Rab7-GFP and GluK3b WT and only $16 \pm 1 \%$ colocalization with the GluK3bVV mutant (50 cells for each condition, $n=3$ experiments, $p<0.0001$, unpaired $t$ test) (Fig. 4D).

The dileucine is an endocytosis motif for GluK3b in primary culture neurons

We next tested the dependence of GluK3b trafficking on the dileucine motif in primary hippocampal cultures of neurons de- 
A

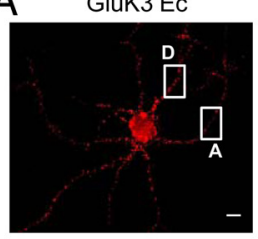

C

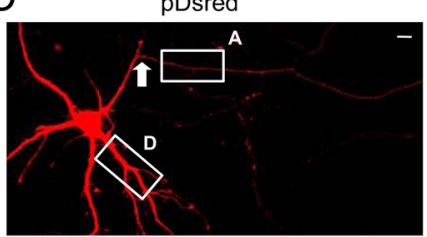

pDsred
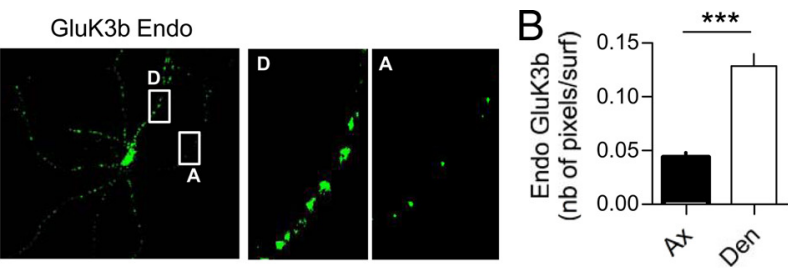

GluK3b (Ec)

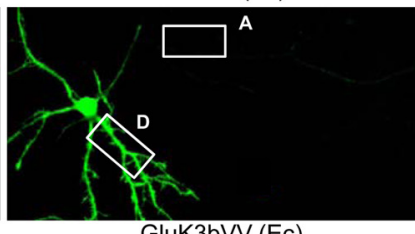
GluK3bVV (Ec)
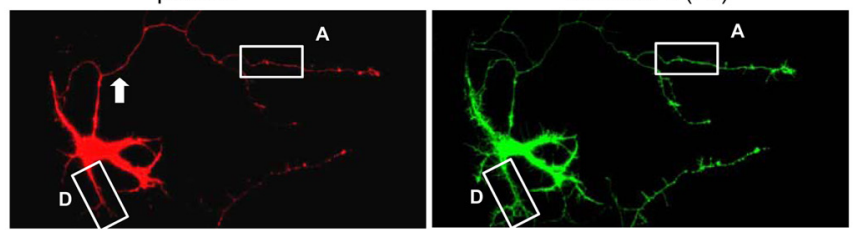

$E$
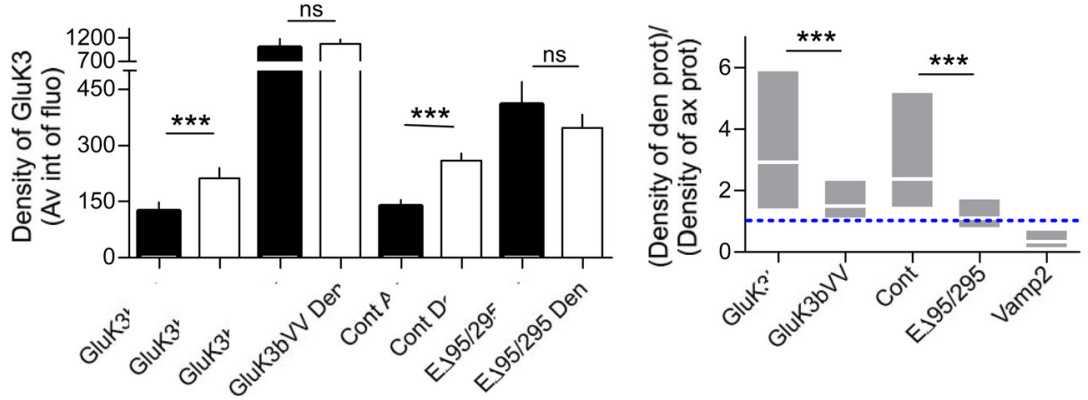

Figure 6. Subcellular localization of GluK3b in neurons depends on endocytosis. $\boldsymbol{A}$, Representative images of extracelIular (Ec) and endocytosed (Endo) myc-GluK3b receptors after transfection in hippocampal neurons. The first image shows the extracellular GluK3b (labeled in red), and the second image shows the endocytosed receptors (labeled in green) in axons (A) and in dendrites (D). The axon was labeled by Ankyrin-G labeling of the initial segment (not shown). Scale bar, 10 $\mu \mathrm{m} . \boldsymbol{B}$, Quantification of the amount of endocytosed receptors in axon and in dendrites (arbitrary units, mean \pm SEM). $\boldsymbol{C}$, Representative images of myc-GluK3 receptors (WT and mutant) transfected in hippocampal neurons. The first column shows the shape of the transfected neurons, labeled in red by expression of pDsred, used both to visualize the cell and to calculate the area. The second column shows the extracellular receptors labeled in green, and the arrows point to the axon of the neurons revealed by Ankyrin-G labeling of the initial segment (not shown). Right panels are merged images corresponding to zoomed boxed areas for axons (A) and dendrites (D). Scale bars, $10 \mu \mathrm{m}$. D, Quantification of the density of myc-GluK3 receptors (WT and mutant) in axons and in dendrites cotransfected with or without Eps 15 (WT or mutant). For each compartment (den: dendrite; ax: axon), the density corresponds to the average intensity of green fluorescence (extracellular GluK3) divided by number of red pixels (area). Histograms show the mean \pm SEM. $\boldsymbol{E}$, Quantification of the ratio between the densities of GluK3 in axons versus dendrites. Vamp2 is used as a control for a specific axonal protein. The graph shows the values of the ratio of densities between dendritic and axonal receptors (mean \pm SEM).

rived from GluK3 ${ }^{-1-}$ mice (Pinheiro et al., 2007). Hippocampal neurons were transfected with myc-GluK3a, myc-GluK3b, or myc-GluK3b-VV (Fig. 5). Receptors expressed at the plasma membrane were labeled with a polyclonal anti-myc antibody and intracellular receptors were labeled with a monoclonal anti-myc antibody (Jaskolski et al., 2004) (Fig. 5A). As in COS-7 cells, the ratio between extracellular (EC, red pixels) and total (red + green pixels) receptors was significantly larger for GluK3bVV than for GluK3b $(p<0.001$, one-way ANOVA Bonferroni's multiplecomparison test), reaching a level similar to that of GluK3a, a protein known to be highly expressed at the plasma membrane (ratio of EC/total receptors, arbitrary units GluK3b: $0.4 \pm 0.02$, $n=39$, GluK3bVV: $0.8 \pm 0.02, n=45$, GluK3a: $0.8 \pm 0.02, n=$ 58 ) (Fig. 5B). To check whether the consequences of the dileucine
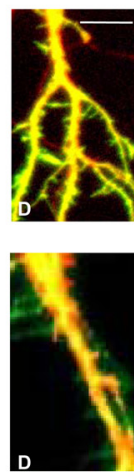

mutation on GluK3b trafficking was related to receptor internalization, we performed an endocytosis assay similar to the one previously described for COS-7 cells (Fig. 5C,D). As in COS-7 cells, we observed that GluK3a was endocytosed at a much lower rate than GluK3b. After 30 $\min$ at $37^{\circ} \mathrm{C}, 14 \pm 3 \%(n=31)$ of GluK3a was endocytosed, as compared to $47 \pm 4 \%$ $(n=38)$ for GluK3b $(n=3$ experiments, $p<0.01)$. Mutation of the dileucine motif decreased the rate of endocytosis to $23 \pm 3 \%$ $(n=44)$ (Fig. 5D). Blocking clathrinmediated endocytosis with dominantnegative proteins resulted in an increased amount of GluK3b at the plasma membrane (percentage endocytosis, GluK3b with D3 2: $58 \pm 2 \%, n=24$; GluK3b with $\mathrm{E} \Delta 95 / 295: 22 \pm 3 \%, n=25$ ) (Fig. $5 E, F)$. Altogether, it appears that the mechanisms of GluK3b trafficking are similar in heterologous cells and in hippocampal neurons.

\section{Polarized expression of GluK3b} depends on endocytosis in neurons Several studies have implicated endocytosis as a possible mechanism for the polarized expression of proteins in either axonal or dendritic compartments (Fache et al., 2004; Bel et al., 2009). Since presynaptic KARs are thought to comprise the GluK3 subunit, we studied whether the endocytosis of GluK3b was responsible for its polarized expression in neurons. We first compared the rate of endocytosis in cultured hippocampal neurons derived from GluK3 ${ }^{-1-}$ mice transfected with GluK3a, GluK3b, or the endocytosisdeficient mutant GluK3bVV. (Fig. 6A,B). We used an antibody directed against ankyrin-G to identify the initial segment, hence the axon, and to identify dendritic compartments (not shown). We observed that endocytosis was more pronounced in the dendritic compartment. After quantification, we found that the rate of endocytosis was significantly higher in dendrites than in axons [amount of endocytosis, in axons: $0.044 \pm 0.002$, in dendrites: $0.13 \pm 0.01(n=28), 3$ experiments, $p<0.0001$, unpaired $t$ test] (Fig. $6 B$ ). To understand whether GluK3b targeting to axons or dendrites was dependent on endocytosis, we quantified the density of surface receptors in axons and dendrites (Fig. 6C,D). We performed immunocytochemistry experiments in cultured hippocampal neurons transfected with either GluK3a (data not shown), GluK3b or the endocytosisdeficient mutant GluK3bVV. To label the entirety of the neuron, we expressed p-DsRed cDNA. The density of GluK3 receptors was calculated by dividing the average intensity of fluorescence corresponding to extracellular receptors (green pixels) per surface unit (expressed DsRed, red pixels) for each region (dendrites and axon). GluK3b is preferentially present in dendrites, whereas GluK3bVV is evenly expressed in axons and dendrites (GluK3b: 
$122 \pm 25$ in axon and $213 \pm 25$ in dendrites, $n=39$ cells, 3 experiments, $p<$ 0.0001 , paired $t$ test; GluK3bVV: $985 \pm$ 100 in axon and $1073 \pm 100$ in dendrites, $n=39$ cells, 3 experiments, $p=0.49$, paired $t$ test) (Fig. $6 D$, arbitrary units). We measured the relative density of extracellular receptors in dendrites versus axons (density of dendritic receptors/density of axonal receptors) (Fig. 6E). We used Vamp2-GFP as a control, which shows a preferential localization in the axon (dendrite/axon ratio for Vamp-2: $0.47 \pm 0.16, n=26$ ). The dendrite/axon ratio of surface GluK3bVV was statistically reduced as compared to GluK3b (GluK3b; $4.15 \pm 1.2, n=39$; GluK3bVV: $1.81 \pm 0.38, n=43,5$ experiments, $p=$ 0.0005 unpaired $t$ test). These experiments strongly suggest that endocytosis controls the polarized expression of GluK3b in cultured neurons.

Interestingly, it seems that two populations of cells differentially expressed GluK3b, with a population showing a dendrite/axon ratio around 1 , and another population with ratio values ranging from to 2 to 20 (data not shown). GluK3b may be directed in part to axonal compartments and then be redirected to dendritic compartments by endocytosis. This mechanism, called transcytosis, has been shown to regulate the trafficking of different types of proteins in neurons (West et al., 1997; Garrido et al., 2003). To confirm the role of endocytosis, we measured the dendrite/axon ratio in neurons cotransfected with GluK3b and either E $\Delta 95 / 295$ (dominant-negative of Eps15) (Fig. $6 D$ ) or D3 2 (as a control). Consistently, we observed a marked decrease of the dendrite/axon ratio of GluK3b in E $\Delta 95 /$ 295-expressing neurons as compared to D3 $\Delta 2$-expressing neurons (E $\Delta$ 95/295: $1.38 \pm 0.3, n=44$; D3 $\Delta 2: 3.6 \pm 0.8, n=66,3$ experiments, $p<0.0001$, unpaired $t$ test). These results demonstrate that interfering with clathrin-dependent endocytosis dramatically changes GluK3b localization in primary cultured neurons, and promotes axonal localization of GluK3b. Moreover, a large number of neurons exhibit a preferential axonal localization of GluK3b in the presence of $\mathrm{E} \Delta 95 / 295$. These results clearly indicate that the polarized expression of GluK3b depends on endocytosis.

We extended these results to the more physiological situation of organotypic hippocampal slices, in which the polarized expression of GluK3 can be studied in dentate granule cells. We used biolistic methods to transfect organotypic hippocampal slices with either GluK3 or GluK3bVV (Fig. 7). Qualitatively, we observed that the localization of reexpressed GluK3b was restricted to dendrites ( $n=8$ neurons) of DG neurons. In contrast, in all transfected DG neurons, GluK3bVV was found to be highly expressed in the axonal compartment (as identified by ankyrinG labeling), in addition to dendrites. Unfortunately, the thickness of the slices did not allow to perform an appropriate quantification of fluorescence in the neuronal compartments. Nevertheless these observations lend further support to the notion that endocytosis regulates the polarized expression of GluK3b localization in neurons.
GluK3b
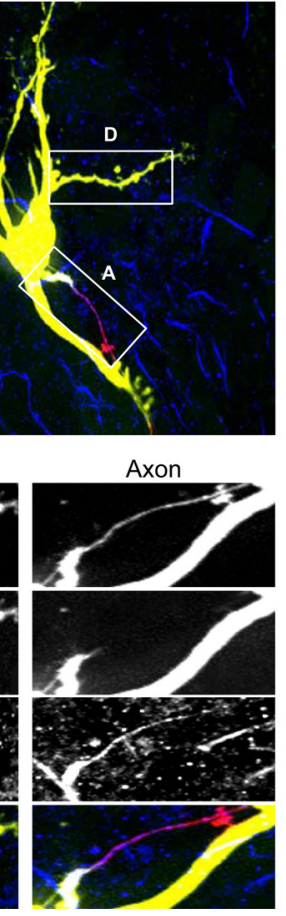

GluK3bVV

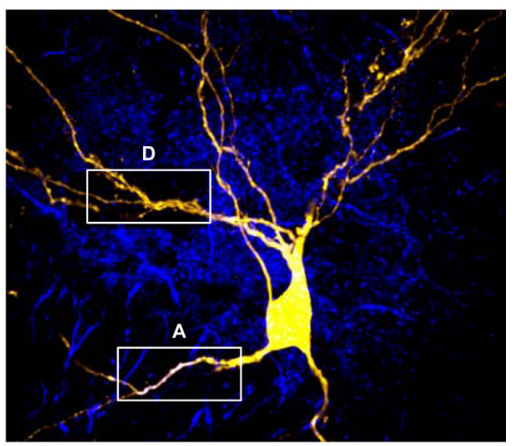

Dendrite
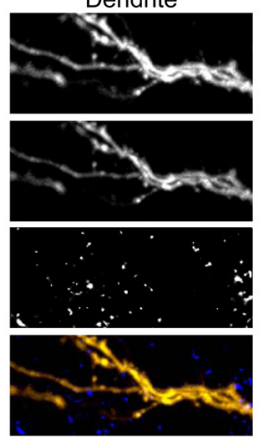

Axon

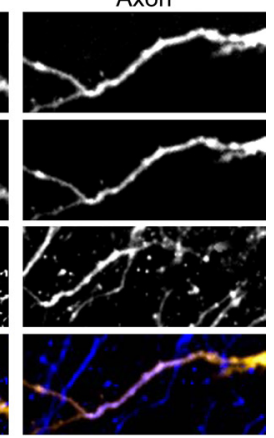

Figure 7. Subcellular localization of GluK3b in neurons from organotypic hippocampal slices: representative images of GluK3b the morphology of the neuron. Expressed receptors are labeled in green. White squares on the top images are enlarged for

\section{Discussion}

In this study, we have examined the molecular mechanisms underlying the cellular trafficking of the GluK3b subunit of KARs in heterologous systems and in neurons. We have provided evidence that the low level of expression of GluK3b at the cell surface is not explained by ER retention through a conventional RXR site, but rather by rapid endocytosis that depends on a dileucine motif, followed by degradation. Moreover, our results demonstrate that the axonal localization of GluK3b is controlled by clathrin-dependent endocytosis.

KAR subtypes subserve a variety of functions that depend in part on their subcellular localization (Contractor et al., 2011). It has not yet been possible to link specific KAR subunits with a particular subcellular localization in neurons. However, it is now clear that KAR splice variants are differentially trafficked in heterologous cell systems and in neurons (Jaskolski et al., 2004). One of the main difference featured among KAR subunit splice variants is their level of expression at the plasma membrane, thus potentially their function. The differential membrane targeting of KAR subunit splice variants, as for many channels and receptors (Ellgaard and Helenius, 2003), relies on retention in the ER based on the presence of lysine (KKXX) or arginine (RXR) amino acid sequences (Ma and Jan, 2002). The arginine-based motifs have been shown to mediate COPI complex binding, which is involved in retrieval transport of ER resident proteins (Vivithanaporn et al., 2006). The RXR site present in GluK1c and GluK5 clearly prevents export of these subunits to the plasma membrane (Ren et al., 2003a,b). In contrast, the low abundance of GluK3b at the plasma membrane cannot be accounted for by the RXR site in the C-terminal domain (Jaskolski et al., 2005c).

Here we show that GluK3b subunit is exported to the plasma membrane, where it is rapidly internalized and degraded explain- 
ing its low abundance at the cell surface. This process is likely combined with retention in the ER, through an unknown mechanism, because the EndoH sensitivity assay reveals a substantial amount of immature GluK3b. Degradation occurs in COS-7 cells, but we do not yet know whether GluK3b is also degraded in neurons or whether the endocytosed receptors are redirected to a specific compartment. A dileucine motif localized in the $\mathrm{C}$ terminus of the protein prevents accumulation of GluK3b in the plasma membrane by promoting endocytosis, via clathrin- and Dynamin2-dependent mechanisms. A dileucine motif, in conjunction with the C-terminal domain, was shown to regulate the intracellular trafficking and lysosomal targeting of opioid receptors (Wang et al., 2003). The constitutive internalization of the cotransporter KCC2 and the binding of adaptor protein-2 complex (AP-2) depend on a novel dileucine motif (Zhao et al., 2008). Finally, a sequence of nine amino acids containing a dileucine motif mediates axonal compartmentalization of voltage-gated sodium channels by selective endocytosis in soma and dendrites (Garrido et al., 2003). The biological implication for this rapid turnover of KAR subunits at the cell surface is unclear but potentially allows for a fine and rapid regulation of GluK3-containing receptors in neuronal membranes.

The molecular mechanisms that govern the polarized trafficking of KARs to specific neuronal compartments remain elusive. As a first step, it would be important to understand the molecular events underlying the axonal vs dendritic localization of KAR subtypes. In neuronal cultures, KAR subunit splice variants do not display a strict segregation in one or the other compartment (Jaskolski et al., 2005a). A more precise quantification of receptor density in the different compartments is likely required to solve this question. Here, we found that both GluK3a and GluK3b are found predominantly in dendrites in control conditions. There are three main mechanisms for the polarized expression of membrane proteins: (1) direct targeting, (2) transcytosis, and (3) balance of endocytosis/recycling/degradation (Grant and Donaldson, 2009). Our results clearly demonstrate that the dendrite/axon ratio of GluK3b expression is under the control of endocytic mechanisms. Preventing endocytosis either by mutating the dileucine motif of GluK3b or by expression of a dominant-negative form of Eps 15 markedly decreased the dendrite/axon ratio and consequently increased the proportion of neurons with polarized expression of GluK3b to axons. In control conditions, there are more surface GluK3b in dendrites than in axons, although the rate of endocytosis is higher in dendrites. This apparent paradox may be explained by continuous targeting of receptors to dendrites and a higher rate of recycling of GluK3b in dendrites. Dendritic GluK3b may be recycled, whereas axonal GluK3b may be internalized and redirected to lysosomes to be degraded, or to dendritic compartments by transcytosis.

The question arises as to whether the rapid endocytosis of GluK3b, which appears to result in the preferential targeting of GluK3b to dendritic compartments, can be regulated in such a way that the axonal localization of GluK3b can be favored. This could potentially be achieved by interaction of GluK3b with cytoplasmic proteins specifically expressed in a subpopulation of neurons that may mask the dileucine motif, as for example the AP-2 complex (Zhao et al., 2008). For KARs, previous studies have linked phosphorylation to the regulation of endocytosis (Martin and Henley, 2004). Endocytosis of glutamate receptors is thought to be triggered in conditions of synaptic plasticity and to underlie long-term depression of synaptic transmission (Malenka and Bear, 2004).

At first sight, this preferential dendritic localization of GluK3b in cultured neurons as well as in hippocampal slice cultures is at odds with the notion that GluK3 is involved in the rapid facilitation of glutamate release at hippocampal mossy fiber synapses (Pinheiro et al., 2007). Several interpretations can, however, be provided for this apparent contradiction: (1) GluK3-containing receptors are thought to be precisely localized near the active zone of the synapse, near glutamate release sites, and not along the axon. It is possible that in some neuronal populations, GluK3b receptors expressed at the plasma membrane in the axon are internalized to be directed to the presynaptic bouton. (2) Homomeric GluK3-containing KARs may lack a targeting signal that could be present in heteromers thought to compose presynaptic receptors (GluK2/GluK3). As an example, it has been shown that GluK1 was expressed in distal dendrites when expressed with GluK2 and GluK5, whereas it is restricted to proximal dendrites when expressed alone (Kayadjanian et al., 2007). (3) Presynaptic KARs composed of GluK3 may be stabilized at specific synapses (i.e., the hippocampal mossy fiber synapses) by transsynaptic mechanisms involving, for instance, the extracellular domain of GluK3 or specific scaffold proteins. (4) Finally, GluK3b targeting could be regulated by activity or by specific signaling mechanisms leading to decreased endocytosis and accumulation in axonal compartments. Such an example exists for mGluR5, which is directed in different neuronal compartments depending on the presence of a Homer, and this relocalization is regulated by neuronal activity (Ango et al., 2000). It is possible that GluK3b interaction with presynaptic interacting proteins could lead to stabilization at the axonal plasma membrane. Our initial experiments in the more physiological context of hippocampal slice cultures indicate that the axonal localization of GluK3bVV is favored in the complex cellular environment of the brain. Future studies should attempt to understand what the molecular and cellular cues regulating the endocytosis of KARs are, hence controlling their expression at presynaptic sites.

\section{References}

Ango F, Pin JP, Tu JC, Xiao B, Worley PF, Bockaert J, Fagni L (2000) Dendritic and axonal targeting of type 5 metabotropic glutamate receptor is regulated by homer1 proteins and neuronal excitation. J Neurosci 20:8710-8716.

Barbosa J Jr, Ferreira LT, Martins-Silva C, Santos MS, Torres GE, Caron MG, Gomez MV, Ferguson SS, Prado MA, Prado VF (2002) Trafficking of the vesicular acetylcholine transporter in SN56 cells: a dynamin-sensitive step and interaction with the AP-2 adaptor complex. J Neurochem 82:1221-1228.

Bel C, Oguievetskaia K, Pitaval C, Goutebroze L, Faivre-Sarrailh C (2009) Axonal targeting of Caspr2 in hippocampal neurons via selective somatodendritic endocytosis. J Cell Sci 122:3403-3413.

Benmerah A, Lamaze C, Bègue B, Schmid SL, Dautry-Varsat A, CerfBensussan N (1998) AP-2/Eps15 interaction is required for receptormediated endocytosis. J Cell Biol 140:1055-1062.

Bertaso F, Zhang C, Scheschonka A, de Bock F, Fontanaud P, Marin P, Huganir RL, Betz H, Bockaert J, Fagni L, Lerner-Natoli M (2008) PICK1 uncoupling from mGluR7a causes absence-like seizures. Nat Neurosci 11:940-948.

Boudin H, Doan A, Xia J, Shigemoto R, Huganir RL, Worley P, Craig AM (2000) Presynaptic clustering of mGluR7a requires the PICK1 PDZ domain binding site. Neuron 28:485-497.

Cao H, Garcia F, McNiven MA (1998) Differential distribution of dynamin isoforms in mammalian cells. Mol Biol Cell 9:2595-2609.

Contractor A, Swanson G, Heinemann SF (2001) Kainate receptors are involved in short- and long-term plasticity at mossy fiber synapses in the hippocampus. Neuron 29:209-216.

Contractor A, Mulle C, Swanson GT (2011) Kainate receptors coming of age: milestones of two decades of research. Trends Neurosci 34:154-163.

Coussen F (2009) Molecular determinants of kainate receptor trafficking. Neuroscience 158:25-35. 
Desimoni G, Faita G, Jørgensen KA (2006) C(2)-symmetric chiral bis(oxazoline) ligands in asymmetric catalysis. Chem Rev 106:3561-3651.

Ellgaard L, Helenius A (2003) Quality control in the endoplasmic reticulum. Nat Rev Mol Cell Biol 4:181-191.

Fache MP, Moussif A, Fernandes F, Giraud P, Garrido JJ, Dargent B (2004) Endocytotic elimination and domain-selective tethering constitute a potential mechanism of protein segregation at the axonal initial segment. J Cell Biol 166:571-578.

Garrido JJ, Giraud P, Carlier E, Fernandes F, Moussif A, Fache MP, Debanne D, Dargent B (2003) A targeting motif involved in sodium channel clustering at the axonal initial segment. Science 300:2091-2094.

Grant BD, Donaldson JG (2009) Pathways and mechanisms of endocytic recycling. Nat Rev Mol Cell Biol 10:597-608.

Hayes DM, Braud S, Hurtado DE, McCallum J, Standley S, Isaac JT, Roche KW (2003) Trafficking and surface expression of the glutamate receptor subunit, KA2. Biochem Biophys Res Commun 310:8-13.

Jaskolski F, Coussen F, Nagarajan N, Normand E, Rosenmund C, Mulle C (2004) Subunit composition and alternative splicing regulate membrane delivery of kainate receptors. J Neurosci 24:2506-2515.

Jaskolski F, Coussen F, Mulle C (2005a) Subcellular localization and trafficking of kainate receptors. Trends Pharmacol Sci 26:20-26.

Jaskolski F, Mulle C, Manzoni OJ (2005b) An automated method to quantify and visualize colocalized fluorescent signals. J Neurosci Methods 146:42-49.

Jaskolski F, Normand E, Mulle C, Coussen F (2005c) Differential trafficking of GluR7 kainate receptor subunit splice variants. J Biol Chem 280:22968-22976.

Kayadjanian N, Lee HS, Piña-Crespo J, Heinemann SF (2007) Localization of glutamate receptors to distal dendrites depends on subunit composition and the kinesin motor protein KIF17. Mol Cell Neurosci 34:219-230.

Ma D, Jan LY (2002) ER transport signals and trafficking of potassium channels and receptors. Curr Opin Neurobiol 12:287-292.

Malenka RC, Bear MF (2004) LTP and LTD: an embarrassment of riches. Neuron 44:5-21.

Martin S, Henley JM (2004) Activity-dependent endocytic sorting of kainate receptors to recycling or degradation pathways. EMBO J 23:4749-4759.

Martin S, Bouschet T, Jenkins EL, Nishimune A, Henley JM (2008) Bidirectional regulation of kainate receptor surface expression in hippocampal neurons. J Biol Chem 283:36435-36440.

Nasu-Nishimura Y, Hurtado D, Braud S, Tang TT, Isaac JT, Roche KW (2006) Identification of an endoplasmic reticulum-retention motif in an intracellular loop of the kainate receptor subunit KA2. J Neurosci 26:7014-7021.

Pelkey KA, Lavezzari G, Racca C, Roche KW, McBain CJ (2005) mGluR7 is a metaplastic switch controlling bidirectional plasticity of feedforward inhibition. Neuron 46:89-102.
Perrais D, Coussen F, Mulle C (2009) Atypical functional properties of GluK3 containing kainate receptors. J Neurosci 29:15499-15510.

Pinheiro PS, Mulle C (2008) Presynaptic glutamate receptors: physiological functions and mechanisms of action. Nat Rev Neurosci 9:423-436.

Pinheiro PS, Perrais D, Coussen F, Barhanin J, Bettler B, Mann JR, Malva JO, Heinemann SF, Mulle C (2007) GluR7 is an essential subunit of presynaptic kainate autoreceptors at hippocampal mossy fiber synapses. Proc Natl Acad Sci U S A 104:12181-12186.

Ren Z, Riley NJ, Garcia EP, Sanders JM, Swanson GT, Marshall J (2003a) Multiple trafficking signals regulate kainate receptor KA2 subunit surface expression. J Neurosci 23:6608-6616.

Ren Z, Riley NJ, Needleman LA, Sanders JM, Swanson GT, Marshall J (2003b) Cell surface expression of GluR5 kainate receptors is regulated by an endoplasmic reticulum retention signal. J Biol Chem 278:52700-52709.

Sansig G, Bushell TJ, Clarke VR, Rozov A, Burnashev N, Portet C, Gasparini F, Schmutz M, Klebs K, Shigemoto R, Flor PJ, Kuhn R, Knoepfel T, Schroeder M, Hampson DR, Collett VJ, Zhang C, Duvoisin RM, Collingridge GL, van Der Putten H (2001) Increased seizure susceptibility in mice lacking metabotropic glutamate receptor 7. J Neurosci 21:8734-8745.

Schiffer HH, Swanson GT, Heinemann SF (1997) Rat GluR7 and a carboxyterminal splice variant, GluR7b, are functional kainate receptor subunits with a low sensitivity to glutamate. Neuron 19:1141-1146.

Schmitz D, Mellor J, Nicoll RA (2001) Presynaptic kainate receptor mediation of frequency facilitation at hippocampal mossy fiber synapses. Science 291:1972-1976.

Suh YH, Pelkey KA, Lavezzari G, Roche PA, Huganir RL, McBain CJ, Roche KW (2008) Corequirement of PICK1 binding and PKC phosphorylation for stable surface expression of the metabotropic glutamate receptor mGluR7. Neuron 58:736-748.

Vivithanaporn P, Yan S, Swanson GT (2006) Intracellular trafficking of KA2 kainate receptors mediated by interactions with coatomer protein complex I (COPI) and 14-3-3 chaperone systems. J Biol Chem 281:15475-15484.

Wang W, Loh HH, Law PY (2003) The intracellular trafficking of opioid receptors directed by carboxyl tail and a di-leucine motif in Neuro2A cells. J Biol Chem 278:36848-36858.

West AE, Neve RL, Buckley KM (1997) Identification of a somatodendritic targeting signal in the cytoplasmic domain of the transferrin receptor. J Neurosci 17:6038-6047.

Yan S, Sanders JM, Xu J, Zhu Y, Contractor A, Swanson GT (2004) A C-terminal determinant of GluR6 kainate receptor trafficking. J Neurosci 24:679-691.

Zhao B, Wong AY, Murshid A, Bowie D, Presley JF, Bedford FK (2008) Identification of a novel di-leucine motif mediating $\mathrm{K}(+) / \mathrm{Cl}(-)$ cotransporter KCC2 constitutive endocytosis. Cell Signal 20:1769-1779. 